\title{
Chronic Nonhealing Wounds: Could Leg Ulcers Be Hereditary?
}

\author{
Nikoletta Nagy, ${ }^{1,2,3}$ Gábor Szabad, ${ }^{3}$ Gyóző Szolnoky, ${ }^{3}$ Zsuzsanna Kiss-László, ${ }^{1}$ \\ Éva Dósa-Rácz, ${ }^{3}$ Zsuzsanna Bata-Csörgő,, ${ }^{2,3}$ Lajos Kemény, ${ }^{2,3}$ and Márta Széll ${ }^{1,2}$ \\ ${ }^{1}$ Department of Medical Genetics, University of Szeged, 4 Somogyi B utca, H-6720 Szeged, Hungary \\ ${ }^{2}$ Dermatological Research Group of the Hungarian Academy of Sciences, University of Szeged, 6 Korányi fasor, H-6720 Szeged, Hungary \\ ${ }^{3}$ Department of Dermatology and Allergology, University of Szeged, 6 Korányi fasor, H-6720 Szeged, Hungary
}

Correspondence should be addressed to Nikoletta Nagy; nikoletta.nagy@gmail.com

Received 4 September 2012; Revised 30 January 2013; Accepted 17 February 2013

Academic Editor: Marco A. C. Frade

Copyright (C) 2013 Nikoletta Nagy et al. This is an open access article distributed under the Creative Commons Attribution License, which permits unrestricted use, distribution, and reproduction in any medium, provided the original work is properly cited.

\begin{abstract}
Background. A number of well-known acquired and putative inherited etiological factors contribute to the development of venous leg ulcer (VLU). Aim. In this study we set out to perform a meta-analysis of putative genetic and acquired factors predisposing to VLU development. Methods. VLU patients $(n=157)$ were divided into three subgroups in accordance with their acquired etiological factors. The frequencies of four genetic factors were determined: the R506Q (Leiden) mutation of the F5 gene, the G20210A mutation of the F2 (prothrombin) gene, the 2451 A/G SNP of the fibroblast growth factor receptor 2 (FGFR2) $3^{\prime}$ UTR, and the $-308 \mathrm{G} / \mathrm{A}$ SNP of the tumor necrosis factor $\alpha$ (TNFA) promoter. Results. The -308 TNFA SNP exhibited a higher frequency among VLU patients without known acquired predisposing factor in their history, than among patients with thrombosis or soft tissue infection in their history (Fisher $P=0.0173$ ). Conclusions. This study has demonstrated that the group of VLU patients is heterogeneous in their genetic predisposing factors. Further large-scale studies are needed to delineate the associations among genetic and acquired etiological factors with regard to VLU development and to integrate the consequences of the already known genetic factors to the management of VLU.
\end{abstract}

\section{Introduction}

Venous leg ulcer (VLU) is multifactorial disease with wellknown acquired and putative inherited predisposing factors [1-15]. Besides the characteristic acquired etiological factors, such as venous insufficiency, obesity, and deep vein thrombosis, case-control studies suggest putative inherited etiological factors, which may also contribute to the mechanism of delayed or pathological wound healing and hence to the development of leg ulcer. A delineation of the genetic susceptibility factors relating to pathological wound healing would therefore promote a better understanding of the molecular background of VLU and that could provide opportunities for developing causative treatment of therapy-resistant forms $[1,2]$.

The difficulties involved in such investigations are increased by the fact that these inherited factors form a complex multifactorial genetic background which does not follow the rules of Mendelien inheritance. Moreover, each genetic component contributes differently to the pathogenesis of VLU, and assessment of its individual relevance in the development of the disease is difficult. To investigate the putative genetic factors and to minimize statistical bias, we set out to form subgroups of VLU patients which were homogeneous in their clinical characteristics and to perform a meta-analysis of four genetic factors within the subgroups.

\section{Methods}

One hundred and fifty-seven VLU patients with therapyresistant nonhealing VLU have been enrolled into the study. Diabetes and arterial leg ulcer were exclusion criteria. The female $(48.41 \%)$ : male $(51.59 \%)$ ratio was close to $1: 1$. The average duration of the VLU was $5.84 \pm 5.12$ years. The clinically relevant parameters and the clinically homogeneous subgroups of VLU patients are shown in Table 1. 
TABLE 1: Clinical characteristics and subgroups of VLU patients.

\begin{tabular}{|c|c|c|}
\hline \multicolumn{3}{|c|}{ Clinical characteristics of VLU patients $(n=157)$} \\
\hline \multicolumn{3}{|c|}{ Cardiac disease $(49.04 \%, n=77)$} \\
\hline \multicolumn{3}{|c|}{ Soft tissue infection $(47.13 \%, n=74)$} \\
\hline \multicolumn{3}{|c|}{ Deep vein thrombosis $(29.94 \%, n=47)$} \\
\hline \multicolumn{3}{|c|}{ Leg fracture $(22.93 \%, n=36)$} \\
\hline \multicolumn{3}{|c|}{ Atherosclerosis $(20.38 \%, n=32)$} \\
\hline \multicolumn{3}{|c|}{ Autoimmune disease $(5.10 \%, n=8)$} \\
\hline \multicolumn{3}{|c|}{ Subgroups of VLU patients } \\
\hline & Leg fracture & $\begin{array}{c}\text { Deep vein } \\
\text { thrombosis or soft } \\
\text { tissue infection }\end{array}$ \\
\hline Group A $(n=72)$ & - & - \\
\hline Group B $(n=33)$ & + & - \\
\hline Group C $(n=52)$ & - & + \\
\hline
\end{tabular}

The frequency and putative interactions of several previously determined genetic factors (the R506Q [Leiden] mutation of the F5 gene, the G20210A mutation of the F2 [prothrombin] gene, the $2451 \mathrm{~A} / \mathrm{G}$ SNP of the FGFR2 $3^{\prime}$ UTR, and the -308 G/A SNP of the TNFA promoter) were earlier assessed in VLU patients [3-6]. The analysis was based on previous results of genotyping performed by either PCR-RFLP or PCR TaqMan methods [3-6]. Chi ${ }^{2}$ tests and multinomial regression analyses performed by SPSS were used to determine frequency and genetic interactions.

The investigation was approved by the Internal Review Board of the University of Szeged. Written informed consent was obtained from all donors, and the study was conducted according to the Principles of the Declaration of Helsinki.

\section{Results}

The R506Q mutation of the F5 gene was detected in heterozygous form in 11 patients with an overall frequency of $7.85 \%$, demonstrating a nonsignificant, higher presentation in group A and group C than in group B (data not shown). The G20210A mutation of the F2 gene occurred in only 3 patients in heterozygous form; all the others carried the wildtype allele (data not shown).

The distributions of the rare genotypes (AG and GG) of the FGFR2 gene polymorphism (2451A/G SNP at the $3^{\prime}$ UTR) were highest in group A (ratio of homozygous mutants $18.84 \%$, rare allele frequency $[\mathrm{MAF}]=0.4638$ ) and lowest in group B (ratio of homozygous rare alleles $8.82 \%$, MAF $=0.3676$, Fisher exact probability test $P=0.1227$, Odds ratio 1.4876, CI 0.8804-1.8075; Figure 1). We have previously reported that the FGFR2 $3^{\prime}$ UTR $2451 \mathrm{~A} / \mathrm{G}$ polymorphism is associated with VLU [5], and the present analysis revealed a similar distribution in the various subgroups of VLU patients, suggesting an overall susceptibility role for this polymorphism in the development of the disease.

The -308 G/A SNP of the TNFA promoter likewise exhibited the highest frequency in group A (ratio of homozygous rare alleles $5.8 \%, \mathrm{MAF}=0.2246$ ), while in groups $\mathrm{B}$ and $\mathrm{C}$ homozygous rare genotype was not detected; only the

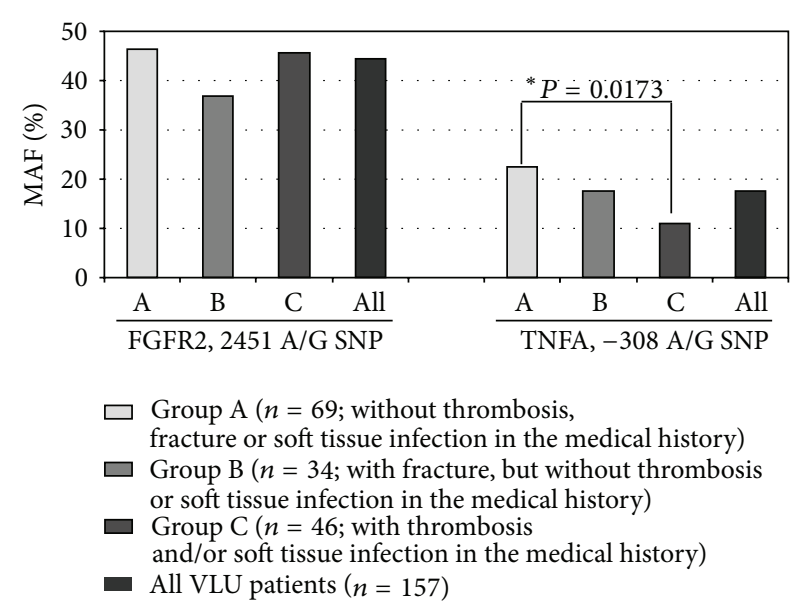

FIGURE 1: Rare allele frequencies of the $2451 \mathrm{~A} / \mathrm{G}$ SNP of FGFR2 and the $-308 \mathrm{~A} / \mathrm{G}$ SNP of TNFA in the subgroups of VLU patients. The FGFR2 3'UTR 2451A/G polymorphism exhibited similar distributions among the subgroups of VLU patients, suggesting an overall role of susceptibility in the disease development. Our data also demonstrated that the homozygous rare allele of the-308 TNFA SNP occurred significantly higher among VLU patients without additional acquired predisposing factors in their history (group A) than among patients with other known etiological events in their history (group C; group A versus group C Fisher exact probability test, $P=0.0173)$.

heterozygous rare genotype was present (group $\mathrm{B}$ MAF = 0.1765 , group $\mathrm{C}, \mathrm{MAF}=0.1087$; group $\mathrm{A}$ versus group $\mathrm{B}, P=$ 0.2711 , odds ratio 1.352 , CI $0.6988-2.3189$; group A versus group C, $P=0.0173$, odds ratio 2.3757, CI 1.0658-4.0073). It was previously demonstrated that the $-308 \mathrm{~A} / \mathrm{G}$ SNP of the promoter region of the TNFA gene is a factor predisposing to VLU development $[6,7]$. Our present data indicate that the homozygous rare genotype of the -308 TNFA SNP occurred significantly more frequently among VLU patients without additional acquired predisposing factors in their history (group A: no thrombosis, fracture, or soft tissue infection) than among patients with other known etiological events in their history (group C: patients with previous thrombosis or soft tissue infection; group A versus group C Fisher exact probability test $P=0.0173$; Figure 1 ). Previously we have reported that the $-308 \mathrm{G} / \mathrm{A}$ SNP of the TNFA promoter is associated with VLU development in obese patients [6]. In the present study, the ratio of obese patients did not show significant difference within the subgroups of the VLU patients. In accordance with our previous results, the highest ratio (38\%) was observed in group $\mathrm{A}$, in which the -308 G/A SNP of the TNFA promoter also exhibited the highest frequency.

Our meta-analysis included an assessment of putative genetic interactions using the multinomial regression method. The R506Q mutation of the F5 gene and the G20210A mutation of the F2 gene were excluded from this analysis because of their low allele frequency. No interaction was found between the $2451 \mathrm{~A} / \mathrm{G}$ SNP of the FGFR2 gene and the -308 G/A SNP of the TNFA gene. The 2451 A/G SNP of the FGFR2 gene proved to be a significantly (5-fold) stronger 
TABLE 2: Putative genetic factors predisposing to VLU development.

\begin{tabular}{lcccc}
\hline & Detected genetic abnormality & Population & Author & Journal \\
\hline$(1)$ & F5 gene R506Q (Leiden) & Year \\
$(2)$ & F2 gene G20210A ${ }^{*}$ & Romanian & Jebeleanu et al. & J Am Acad Dermatol \\
$(3)$ & F13A gene V34L & Italian & Gemmati et al. & W Cell Mol Med \\
$(4)$ & FGFR2 gene 3' UTR A2451G* & Hungarian & Nagy et al. & J Invest Dermatol \\
$(5)$ & ESRB gene CA repeat D14S1026 & UK & Ashworth et al. & J Steroid Biochem Mol Biol \\
$(6)$ & HFE gene C282Y & Italian & Zamboni et al. & J Vasc Surg \\
$(7)$ & TNFA gene promoter $-308^{*}$ & Australian & Wallace et al. & J Invest Dermatol \\
$(8)$ & FPN1 gene promoter -8 GG & Hungarian & Nagy et al. & J Invest Dermatol \\
$(9)$ & MMP12 gene promoter $-82 \mathrm{AA}$ & Italian & Gemmati et al. & J Vasc Surg \\
$(10)$ & Sex chromosome aberrations & Italian & Gemmati et al. & J Vasc Surg \\
& $(47, X X Y / 48, X X X Y$ karyotype $)$ & Austrian & Gattringer et al. & Acta Derm Venereol \\
\hline
\end{tabular}

* The distributions of the genotypes and the allele frequencies of these genetic factors were compared in the present study.

susceptibility factor than the $-308 \mathrm{G} / \mathrm{A}$ SNP of the TNFA gene.

\section{Discussion}

Up to now little is known about the genetic background of VLU; however there have been several papers published in this topic. The first report on the genetic backgrounds of VLU was on the Leiden and the prothrombin gene mutation; the first findings demonstrated their association with venous thrombosis and later with postthrombotic leg ulcer development $[3,8]$. The FGFR2 gene encodes keratinocyte growth factor receptor involved in the proliferation of keratinocytes and wound healing, while the TNFA gene encodes a wellknown proinflammatory cytokine. The investigated SNPs of the FGFR2 and TNFA genes were previously proved to be associated with VLU $[5,6]$.

Other genetic factors-not investigated in this studyhave been also reported to be associated with VLU (Table 2). The V34L SNP of the F13A gene was proved to be associated with the progression of VLU due to its direct effect on the activity of F13 [9]. Estrogen is a well-known accelerator of wound healing by dampening the inflammatory response; a common variant of its receptor (ESRB) increases the risk of VLU development [10]. The C282Y SNP of the HFE gene increases the risk of VLU by affecting iron protective mechanisms [11]. A DNA-array reported by Gemmati et al. (2009) revealed that the $-82 \mathrm{~A} / \mathrm{G}$ SNP of the MMP12 and the $-8 \mathrm{G} / \mathrm{C}$ SNP of the FPN1 genes are also associated with VLU [12]. Moreover, chromosomal abnormalities have also been found in VLU patients with unusual early onset [16].

The aim of this study was to assess the relevance of already known genetic factors and their interactions in VLU development in clinically homogeneous subgroups of patients. Deep vein thrombosis, soft tissue infection, and leg fracture frequently found clinical characteristics among VLU patients, were suitable for the creation of clinically homogeneous subgroups within our study population. Cardiac disease was also frequent, but displayed a very similar distribution in the VLU patient subgroups. Of the four investigated genetic factors, the $2451 \mathrm{~A} / \mathrm{G}$ SNP of the FGFR2 gene proved most relevant.

Our data further emphasize the importance of clinically homogeneous subgroups of patients for the analysis of putative genetic factors in order to assess mutual relevance, to create hierarchy, and to measure potential interactions. Further larger-scale studies are needed to assess the contributions of different putative genetic factors to the variable appearance of VLU phenotypes. Such analyses could hold the key to the understanding of VLU development. They might also serve a crucial role in the development of future causative treatment strategies through the creation of cost-effective investigation techniques for routine diagnostic assessment of putative genetic factors and causative treatment options.

\section{Conflict of Interests}

The authors have declared no conflicting interests.

\section{Acknowledgment}

The authors acknowledge TÁMOP-4.2.1/B-09/1/KONV2010-0005 the Grant.

\section{References}

[1] F. G. R. Fowkes, C. J. Evans, and A. J. Lee, "Prevalence and risk factors of chronic venous insufficiency," Angiology, vol. 52, supplement 8, pp. S5-S15, 2001.

[2] L. P. Abbade, S. Lastória, H. de Almeida Rollo, and H. O. Stolf, "A sociodemographic, clinical study of patients with venous ulcer," International Journal of Dermatology, vol. 44, no. 12, pp. 989992, 2005.

[3] G. Jebeleanu and L. Procopciuc, "G20210A prothrombin gene mutation identified in patients with venous leg ulcers," Journal of Cellular and Molecular Medicine, vol. 5, no. 4, pp. 397-401, 2001.

[4] J. Hafner, A. Kühne, B. Schär et al., "Factor V Leiden mutation in postthrombotic and non-postthrombotic venous ulcers," Archives of Dermatology, vol. 137, no. 5, pp. 599-603, 2001. 
[5] N. Nagy, G. Szolnoky, G. Szabad et al., "Single nucleotide polymorphisms of the fibroblast growth factor receptor 2 gene in patients with chronic venous insufficiency with leg ulcer," Journal of Investigative Dermatology, vol. 124, no. 5, pp. 10851088, 2005.

[6] N. Nagy, G. Szolnoky, G. Szabad et al., "Tumor necrosis factor$\alpha$-308 Polymorphism and leg ulceration- possible association with obesity," Journal of Investigative Dermatology, vol. 127, no. 7, pp. 1768-1769, 2007.

[7] H. J. Wallace, Y. K. Vandongen, and M. C. Stacey, “Tumor necrosis factor-alpha gene polymorphism associated with increased susceptibility to venous leg ulceration," The Journal of Investigative Dermatology, vol. 126, no. 4, pp. 921-925, 2006.

[8] D. Peus, S. V. Schmiedeberg, A. Pier et al., "Coagulation factor $\mathrm{V}$ gene mutation associated with activated protein $\mathrm{C}$ resistance leading to recurrent thrombosis, leg ulcers, and lymphedema: successful treatment with intermittent compression," Journal of the American Academy of Dermatology, vol. 35, no. 2, pp. 306309, 1996.

[9] D. Gemmati, S. Tognazzo, M. L. Serino et al., "Factor XIII V34L polymorphism modulates the risk of chronic venous leg ulcer progression and extension," Wound Repair and Regeneration, vol. 12, no. 5, pp. 512-517, 2004.

[10] J. J. Ashworth, J. V. Smyth, N. Pendleton et al., "The dinucleotide (CA) repeat polymorphism of estrogen receptor beta but not the dinucleotide (TA) repeat polymorphism of estrogen receptor alpha is associated with venous ulceration," Journal of Steroid Biochemistry and Molecular Biology, vol. 97, no. 3, pp. 266-270, 2005.

[11] P. Zamboni, S. Tognazzo, M. Izzo et al., "Hemochromatosis C282Y gene mutation increases the risk of venous leg ulceration," Journal of Vascular Surgery, vol. 42, no. 2, pp. 309-314, 2005.

[12] D. Gemmati, F. Federici, L. Catozzi et al., "DNA-array of gene variants in venous leg ulcers: detection of prognostic indicators," Journal of Vascular Surgery, vol. 50, no. 6, pp. 14441451, 2009.

[13] K. I. Cheng, S. R. Lin, L. L. Chang, J. Y. Wang, and C. S. Lai, "Association of the functional A118G polymorphism of OPRM1 in diabetic patients with foot ulcer pain," Journal of Diabetes and its Complications, vol. 24, no. 2, pp. 102-108, 2010.

[14] K. A. Mir, S. Pugazhendhi, M. J. Paul, A. Nair, and B. S. Ramakrishna, "Heat-shock protein 70 gene polymorphism is associated with the severity of diabetic foot ulcer and the outcome of surgical treatment," British Journal of Surgery, vol. 96, no. 10, pp. 1205-1209, 2009.

[15] D. Corapcioglu, M. Sahin, R. Emral, Z. K. Celebi, O. Sener, and V. T. Gedik, "Association of the G894T polymorphism of the endothelial nitric oxide synthase gene with diabetic foot syndrome foot ulcer, diabetic complications, and comorbid vascular diseases: a Turkish case-control study," Genetic Testing and Molecular Biomarkers, vol. 14, no. 4, pp. 483-488, 2010.

[16] C. Gattringer, C. Scheurecker, R. Höpfl, and H. Müller, "Association between venous leg ulcers and sex chromosome anomalies in men," Acta Dermato-Venereologica, vol. 90, no. 6, pp. 612-615, 2010. 


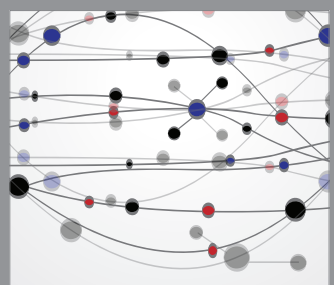

The Scientific World Journal
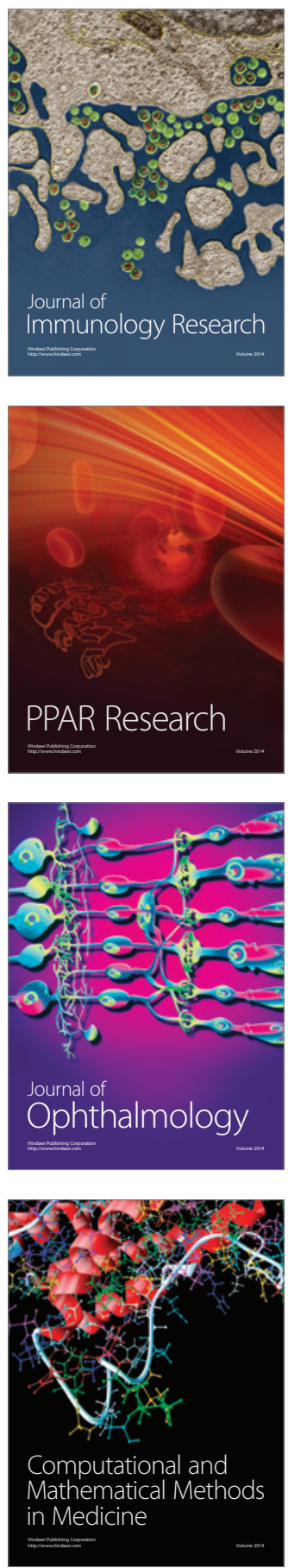

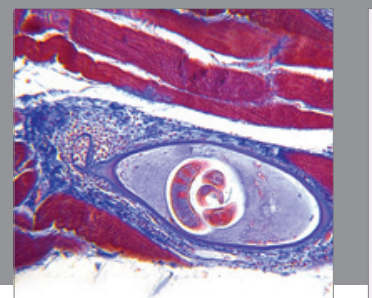

Gastroenterology

Research and Practice
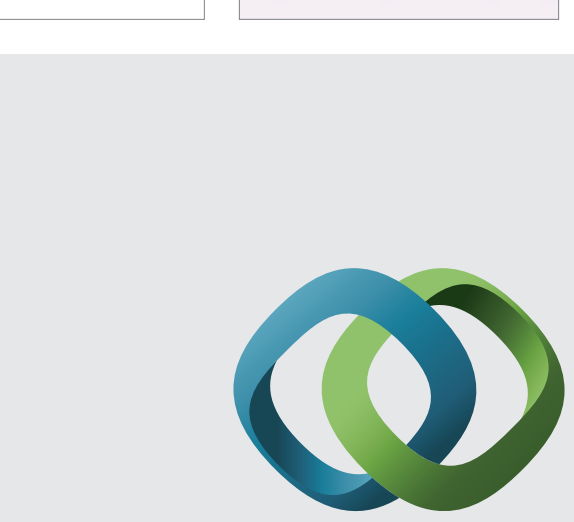

\section{Hindawi}

Submit your manuscripts at

http://www.hindawi.com
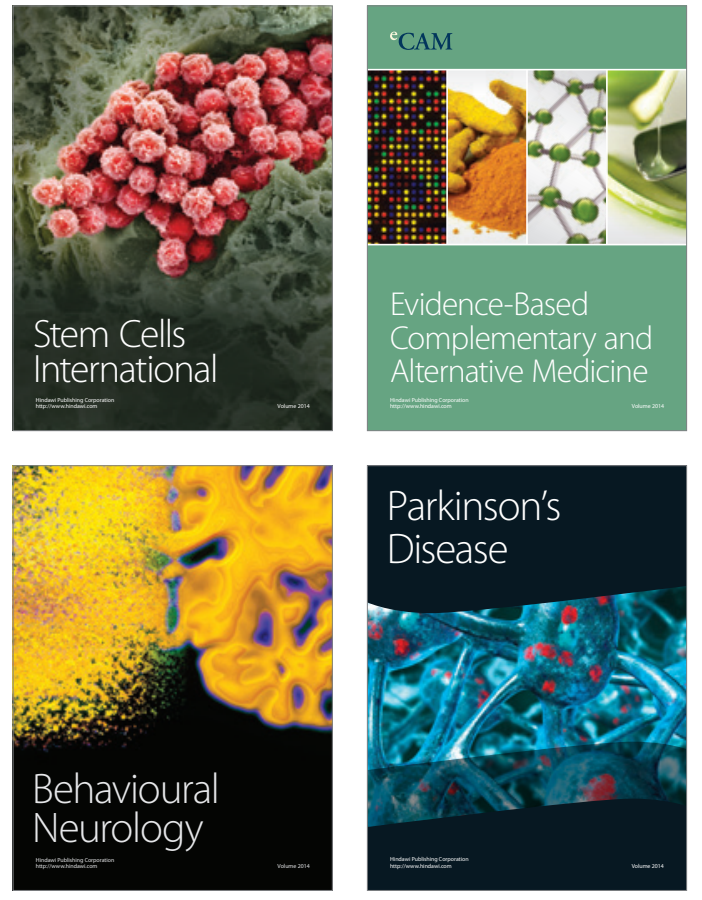
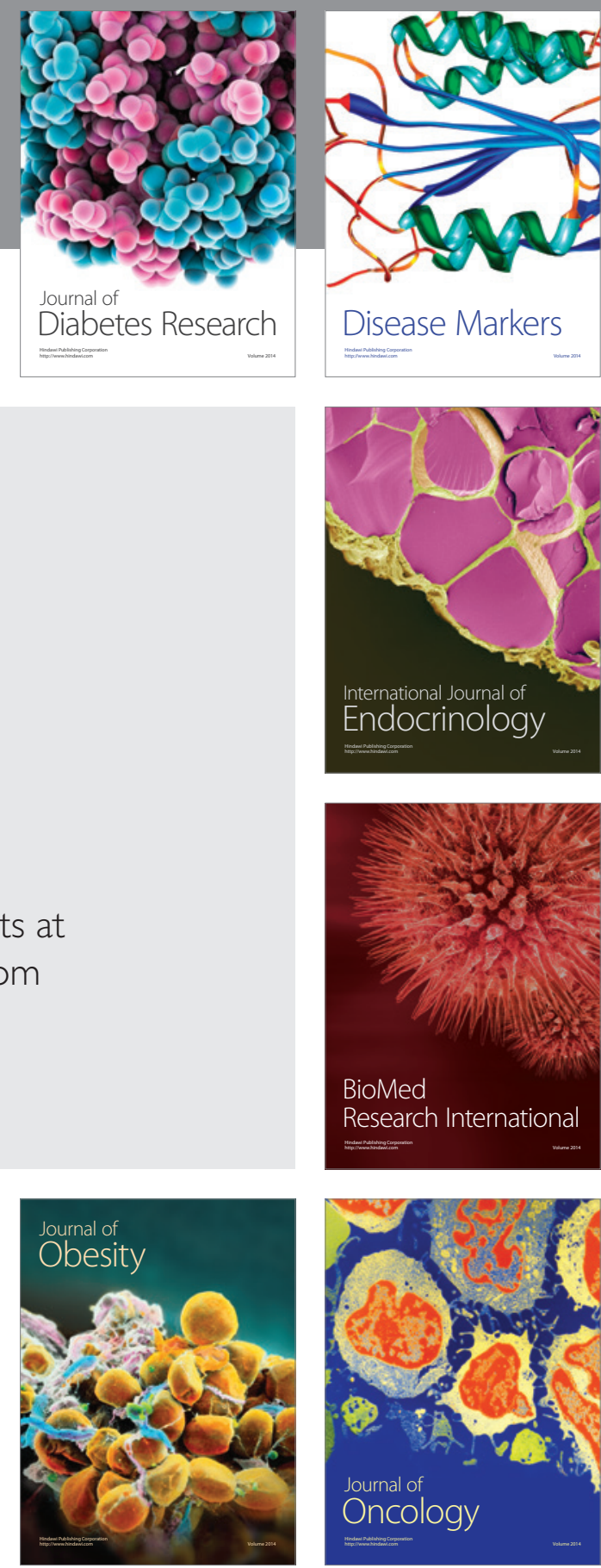

Disease Markers
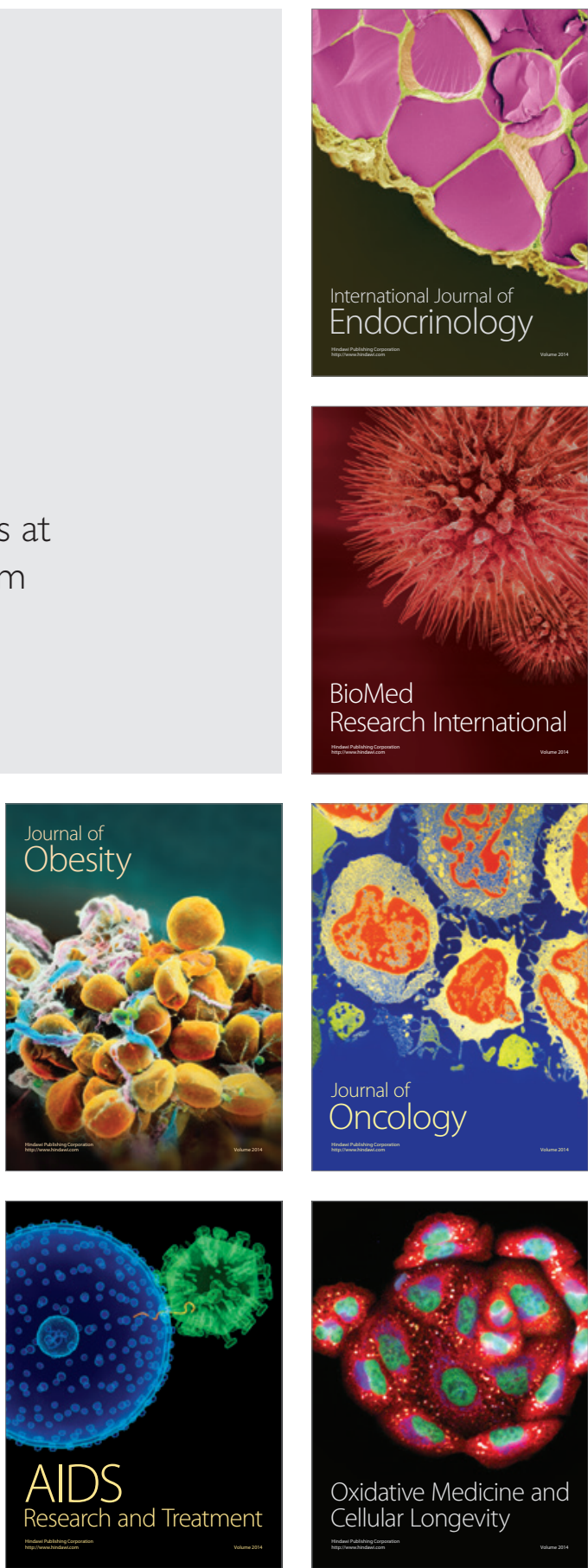